\title{
Systemic Conditions, Oral Findings and Dental Management of Chronic Renal Failure Patients: General Considerations and Case Report
}

\author{
Mahmud Juma Abdalla Abdel HAMID ${ }^{1}$ \\ Claus Dieter DUMMER ${ }^{2}$ \\ Lourenço Schmidt PINTO ${ }^{1}$ \\ ${ }^{1}$ Discipline of Bucomaxilofacial Surgery, Department of Nursing and Dentistry, \\ University of Santa Cruz do Sul, Santa Cruz do Sul, RS, Brazil \\ ${ }^{2}$ Graduate Program in Medical Science, Nephrology Area, \\ Federal University of Rio Grande do Sul, Porto Alegre, RS, Brazil
}

\begin{abstract}
Chronic renal failure is a relatively common systemic disease. Systemic abnormalities such as anemia, platelet disorders and hypertension as well as oral manifestations including xerostomia, uremic stomatitis, periodontal disease and maxillary and mandibular radiographic alterations can be observed in individuals with chronic renal disease. In view of its frequent occurrence and the need of knowledge by dentists dealing with this condition, this paper discusses the most important issues regarding chronic renal failure, addressing its systemic and oral manifestations and the dental management of chronic renal patients. A case report is presented.
\end{abstract}

Key Words: chronic renal failure, hypertension, diabetes mellitus, dialysis, dental management.

\section{INTRODUCTION}

Chronic renal failure is defined as the progressive and usually irreversible decline of the glomerular filtration rate, leading to an increase of serum creatinine and blood ureic nitrogen levels. The most frequent causes of chronic renal failure are hypertension, diabetes mellitus, chronic glomerulonephritis, uropathy and autoimmune diseases (1-3). It is a relatively common condition (4) and diabetic nephropathy is the most frequent cause of the end-stage of renal disease (ESRD), being found in $14 \%$ of renal failure patients in England (5) and 34\% of the patients in the USA (5)

Because of its usually irreversible and progressive nature, the evolution to the ESRD occurs where glomerular filtration rate is around $5-10 \%$ and there is a high level of uremia (5). These are signals and symptoms derived from physiological and biochemical abnormalities of serious renal failure. Chronic renal disease is associated with multiple complications that are influenced by its etiology, decreased renal function, response to treatment and individual variation (6). In view of its frequent occurrence and the need of knowledge by dentists dealing with this condition, this paper discusses the most important issues regarding chronic renal failure, addressing its systemic and oral manifestations and the dental management of chronic renal patients. A case report is presented.

\section{CASE REPORT}

A 35-year-old Caucasian female was referred to our clinic for dental treatment. She had a medical history of moderate renal function loss since 1991 and diabetes mellitus and hypertensive crises since the age of 13, which were controlled exclusively with diet. The patient needed hospitalization in several occasions due to frank uremia, metabolic acidosis and hypertensive crisis,

Correspondence: Prof. Mahmud Juma Abdalla Abdel Hamid, Rua Marechal Floriano Peixoto, 621, 96810-000 Santa Cruz do Sul, RS, Brasil. Tel: +55-51-3713-3875. email: mutti05@ibest.com.br 
being diagnosed with renal chronic failure and starting hemodialysis. Diabetic nephropathy was established as an etiologic fator for chronic renal disease and she was transferred to continuous ambulatory peritoneal dialysis (CAPD) by decision of the medical team.

According to her medical records, the patient was examined by an otorhinolaryngologist in 1994 due to complaints of hypoacusis. Neurosensorial cochlear deafness was diagnosed and the use of a hearing device was indicated. After years of evolution, the patient presented glaucoma in the left eye and was referred to corrective surgery. She was kept in the continuous ambulatory peritoneal dialysis for a while but, due to repetitive bacterial peritonitis, she had to return to hemodialysis. She is currently undertaking 4-hour hemodialysis sessions, three times a week using a polytetrafluoroethylene prosthesis as an arteriovenous fistula in the left arm.

The patient also had complications due to diabetes mellitus such as amaurosis and peripheral vascular problems. Because of the years of chronic renal disease and hemodialysis, she had signals of secondary hyperparathyroidism. The drug regimen prescribed by her attending physicians was maintained (furosemide $40 \mathrm{mg}$ qd, captopril $25 \mathrm{mg}$ bid, B complex bid, folic acid $5 \mathrm{mg} \mathrm{qd}$, calcitriol $0.25 \mu \mathrm{g}$ qd and calcium carbonate 2 $\mathrm{g}$ at breakfast, lunch or dinner).

Regarding the dental history, the patient had painful symptomatology in the anterior region of the mandible. She reported pain on chewing and sensitivity to thermal stimuli. Intraoral clinical examination showed mobility of some teeth, generalized loss of insertion, deep periodontal pockets, furcation lesions, gingival bleeding and heavy dental plaque deposits throughout the mouth (Fig. 1). The panoramic radiograph revealed

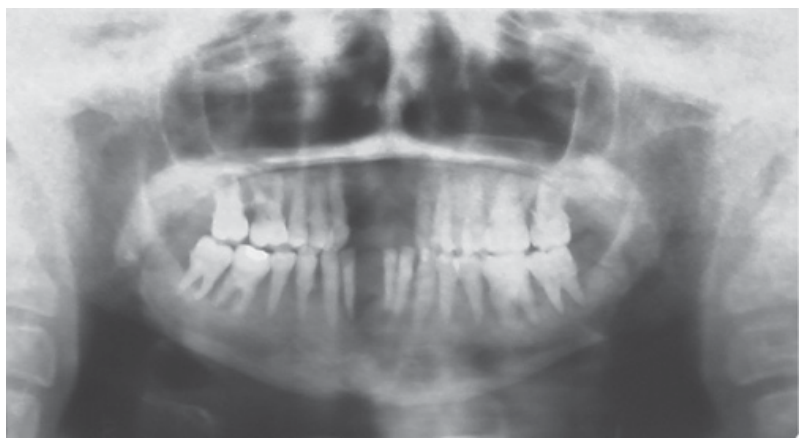

Figure 2. Panoramic radiograph showing accentuated bone loss, interproximal calculus and periapical abscesses. accentuated bone loss at the alveolar crest compromising bone support, radiopaque images between the teeth suggestive of interproximal calculus and periapical abscesses associate with some teeth (Fig. 2).

Almost all teeth were severely destroyed and/or periodontally compromised. The patient and her family were clarified about her oral conditions and a decision was made for full-mouth tooth extraction and subsequent prosthetic rehabilitation. Before exodontia, medical consent was obtained and routine laboratory tests were done. The surgical procedures were scheduled in blocks under general anesthesia. The postoperative course was uneventful. Five months after extractions, the panoramic radiographic control did not show radiographic alterations suggestive of bone malformation (Fig. 3).

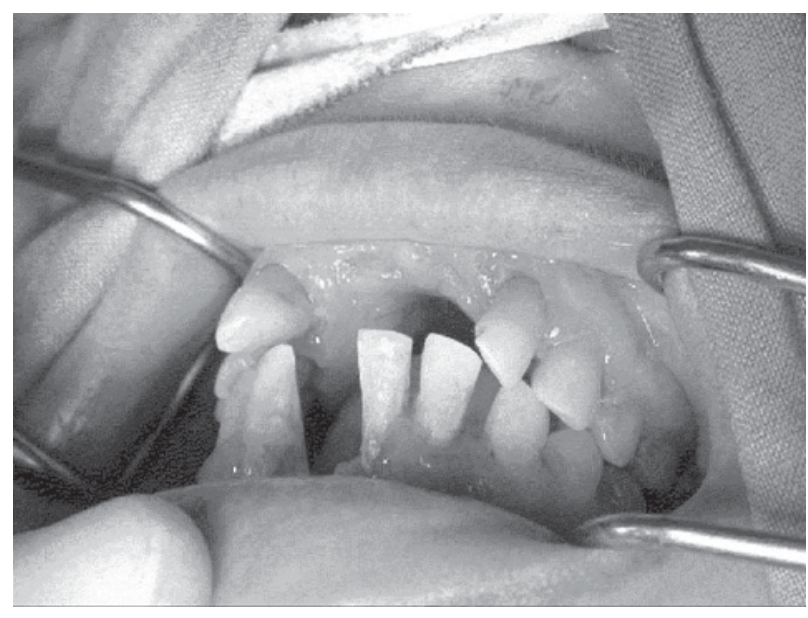

Figure 1. Intraoral clinical examination revealed tooth mobility, deep periodontal pockets, furcation lesions, gingival bleeding and heavy plaque deposits.

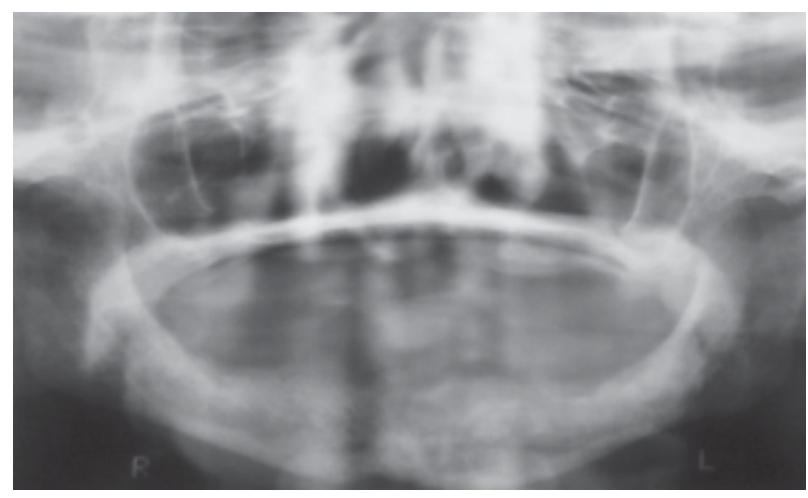

Figure 3. Panoramic radiograph taken 5 months after full-mouth tooth extraction, showing lack of bone malformation. 


\section{DISCUSSION}

Uremia can affect the central nervous system causing loss of memory, illusion, slurred speech, depression, low concentration, coma, asterixis, epilepsy (2), and can also be associated with the development of metabolic acidosis and hyperkalemia (7). In addition, uremia can affect the gastrointestinal system provoking nauseas, vomits, peptic ulcers and metallic taste in the mouth, and cause dermatological alterations such as pallor, pruritus and calcium deposition in tissues $(2,5,7)$.

ESRD patients present a number of hematopoietic abnormalities, most commonly anemia and hemostasis problems (7). Although anemia is considered a multifactorial disease, its major cause is a decreased erythropoietin production due to loss of functional renal tissue (7). There are also changes in leukocyte production, notably with associated lymphocytopenia $(1,7)$. Uremia causes suppression of lymphocytic response, dysfunction of granulocytes and suppression of cell-mediated immunity $(1,7)$. These alterations place uremic patients at a higher risk for infection $(1,7)$. Hemostasis problems are usually observed in chronic renal failure patients due to abnormal platelet adhesion and aggregation (Von Willebrand factor defect), decrease of platelet factor III and alteration in prothrombin metabolism (5).

Changes in bone metabolism are common and caused mainly by secondary hyperparathyroidism (8), which, in turn, results from a high phosphorus serum level (due to decreased renal clearance) and low serum calcium and calcitriol levels (due to decreased hydroxylation of 25-hydroxyvitamin $\mathrm{D}_{3}$ in the kidneys) (8). These alterations can occur concomitantly and lead to bone resorption and osteitis fibrosa $(2,5,7)$. They might present either as generalized demineralization or as frank intrabony lesions (in more advanced stages), sometimes containing focal tumors that are histologically similar to giant cell tumors of the bone (9). If renal disease develops during the growth phase, the patient might have delayed growth or rickets (renal osteodystrophy), delayed tooth eruption and sexual maturity (10). The aggravation of renal disease can lead to congestive heart failure associated to pulmonary edema, ascites, arrhythmias, arteriosclerosis, myocardiopathy and pericarditis $(5,7)$. Severe chronic renal disease can also cause hypertension due to fluid overload $(5,7)$.
The systemic manifestations unchain alterations in the oral cavity: calculus, high urea concentration in saliva, ammonia-like smell, xerostomia, oral bleeding, stomatitis, pale gingivae, drug-induced gingival hyperplasia, loss of lamina dura, maxillary and mandibular radiolucent lesions, abnormal bone remodeling after extraction, enamel hypoplasia, delayed tooth eruption pattern, low caries prevalence, dental erosion, sensitivity to percussion and mastication, tooth mobility and malocclusion $(5,7,10)$.

The findings of a previous study showed that the $\mathrm{pH}$ of the saliva of ESRD patients was alkaline because of the high concentration of ammonia as a result of ureal hydrolysis (11). Such an elevated salivary phosphate concentration could also contribute to increase the buffer capacity and partially explain the low caries incidence. Nevertheless, Klassen and Krasko (12), in a study evaluating the dental health status of dialysis patients, found that the renal patients had worse oral hygiene than the healthy control patients, presenting greater calculus formation, gingivitis and larger number of caries lesions.

Gavaldá et al. (13) examined the oral mucosa of individuals with chronic renal failure and noted several mucosal lesions, uremic stomatitis and Candida infections in $37 \%$ of these patients. Klassen and Krasko (12) evaluated 45 patients undertaking hemodialysis and reported that $100 \%$ of them presented some type of periodontal disease, $64 \%$ had severe gingivitis and $28 \%$ had early periodontitis regardless of the duration of dialysis. In another study with 44 dialysis patients, periodontal disease (i.e., severe gingivitis characterized by marked redness, inflammation, bleeding and ulcers) was present in all cases (14).

Radiographic alterations in the maxilla and mandible - loss of lamina dura, radiolucent lesions and abnormal post-extraction bone healing - are caused by loss of calcium from the bone tissues due to an increase of parathormone production. This results in the calcium, phosphate and vitamin D metabolism disorders $(1,2,5)$. Both primary and secondary hyperparathyroidism have been shown to cause loss of lamina dura. Nevertheless, although considered as a pathognomonic sign for hyperparathyroidism in the past, it is now recognized as non-specific (9). Decrease or loss of cortical bone is observed at the mandibular angle and around the maxillary sinuses, mental foramen and mandibular canal (13). It is important to point out that bone demineralization can 
lead to rapid bone destruction and periodontitis (14).

The treatment proposed for a patient with chronic renal failure will depend on the stage of the renal disease and on his/her current clinical status $(4,5)$. Patients with decreased renal reserve, but without clinical signals and symptoms, can be normally treated as long as drugs with renal metabolism are not prescribed $(4,5)$ because drugs that are metabolized in kidneys can cause toxicity and aggravate the patient's condition, even if administered in usual doses $(5,7)$. When these drugs cannot be replaced, their dosage should be adjusted to each individual $(5,7)$.

The early evaluation of oral health status of renal patients is essential to eliminate potential infection foci from the oral cavity (15). The need for prophylactic antibiotictherapy to prevent local or distant infection, patient's ability to tolerate dental treatment, coagulation profile and severity of cardiac arrhythmias should also be assessed (2).

Patients undergoing dialysis are exposed to a large number of blood transfusions and are therefore at a higher risk of contracting hepatitis B and C $(16,17)$. In addition, bacterial endocarditis has been reported as an uncommon but serious complication in the dental management of individuals undertaking hemodialysis $(12,18)$. They are considered moderate-risk patients and the prescrition of a prophylactic antibiotictherapy is particularly important for ESRD patients under treatment with dialysis. On the other hand, patients undertaking peritoneal dialysis do not need prophylaxis with antibiotics (17).

The hematological conditions that most commonly affect patients with uremia and renal failure are excessive bleeding and anemia (1), which are attributed to a combination of factors, including the anticoagulants used for hemodialysis and vascular access maintenance (2). In patients with significantly increased bleeding or clotting times, antifibrinolytic agents, fresh-frozen plasma, vitamin $\mathrm{K}$ and platelet replacement may be prescribed or electrocautery may be used to control hemorrhage during invasive oral procedures $(2,19)$. Whether the patient is using coumarin group anticoagulants (warfarin) or sodium heparin should also carefully assessed. The anticoagulant effects of heparin used during dialysis do not produce residual bleeding abnormalities because they last only 3-4 hours postinfusion $(2,19)$. The decision to use the antifibrinolytic method, with no INR (international normalized ratio) adjustment, should be made after considering the level of hemorrhage to be created, INR, risk of thromboembolism and the nephrologist's opinion (2) Dental treatment will be safer if performed on the day following dialysis when there is no risk of prolonged bleeding, blood impurities have been eliminated (16), heparin administered during dialysis has already been metabolized and the patient is in better health conditions regarding the intravascular volume and products resulting from heparin metabolism (16).

Renal failure patients have a progressive disease that may require dialysis or a renal transplant $(12,14)$. Dental treatment of these patients should preferably be carried out before the transplant $(12,14,20)$. Infection is the major complication of renal transplant patients $(12,20)$, which means that a periodontal abscess, for example, is a potentially life-threatening condition (20).

Therefore, it is important that renal patients needing transplant are examined by an experienced dentist before surgery to determine which teeth can be preserved without representing an infection focus after transplantation (20). Teeth with furcation lesions, periodontal abscesses or requiring more invasive surgical procedures indications must be extracted (20).

\section{RESUMO}

A insuficiência renal crônica é uma doença sistêmica relativamente comum. Manifestações sistêmicas tais como anemia, hipertensão, distúrbios plaquetários e manifestações bucais como xerostomia, estomatite urêmica, doença periodontal, alterações radiográficas na maxila e mandíbula podem ser observadas em pacientes com insuficiência renal crônica. Frente à freqüência desta condição e à necessidade de informações para o cirurgiãodentista lidar com essa condição, este artigo discute os aspectos mais importantes da insuficiência renal crônica, abordando suas manifestações sistêmicas e orais e o tratamento odontológico de pacientes renais crônicos. A descrição de um caso clínico é apresentada.

\section{REFERENCES}

1. Rossi SS, Glick M. Dental Considerations for the patient with renal disease receiving hemodialysis. J Amer Dent Assoc 1996;19:127-211.

2. Ferguson CA, Whyman RA. Dental management of people with renal disease and renal transplants. $N$ Z Dent J 1998;94:125-130.

3. Proctor R, Kumar N, Stein A, Moles D, Porter S. Oral and dental aspects of chronic renal failure. J Dent Res 2005;84:199-208.

4. Greenwood M, Meechan JG, Bryant DG. General medicine and surgery for dental practitioners Part $7 . \mathrm{Br}$ Dent $\mathrm{J}$ 
2003;195:181-184.

5. Bottomley WK, Cioffi RF, Martin AJ. Dental management of the patient treated by renal transplantation: preoperative and postoperative considerations. J Am Dent Assoc 1972;85:1330-1335.

6. Kalyvas D, Tosios KL, Leventis MD, Tsiklakis K, Angelopoulos AP. Localized jaw enlargement in renal osteodystrophy: report of a case and review of the literature. Oral surg Oral Med Oral Pathol Oral Radiol Endod 2004;97:6874.

7. Naylor GD, Fredericks MR. Pharmacologic considerations in the dental management of the patient with disorders of the renal system. Dent Clin North Amer 1996;40:665-683.

8. Daugirdas JT, Blake PG, Ing TS. Handbook of dialysis. 3rd ed. Rio de Janeiro: Medsi; 2003.

9. Frankenthal S, Nakhoul F, Machtei EE, Green J, Ardekian L, Laufer D, Peled M. The effect of secondary hyperparathyroidism and hemodialysis therapy on alveolar bone and periodontium. J Clin Periodontol 2002;29:479-483.

10. Heard E Jr, Staples AF, Czerwinski AW. The dental patients with renal disease. Precautions and guidelines. J Am Dent Assoc 1978;96:792-796.

11. Kho H, Lee S, Cheng S, Kim Y. Oral manifestations and salivary flow rate, $\mathrm{pH}$, and buffer capacity in patients with end-stage renal disease undergoing hemodialysis. Oral surg Oral Med Oral Pathol Oral Radiol Endod 1999;88:316-319.

12. Klassen JT, Krasko BM. The dental health status of dialysis patients. J Can Dent Assoc 2002;68:34-38.

13. Gavaldá C, Bagán JV, Scully C, Silvestre FJ, Milián MA, Jiménez. Renal hemodialysis patients: oral, salivary, dental and periodontal findings in 105 adult cases. Oral Dis 1999;5:299-302.

14. Wilson TG, Kornman KS. Fundamentals of periodontics. 2nd ed. Chicago: Quintessence Publishing Co.; 2003.

15. Naugle K, Darby ML, Bauman DB, Lineberger LT, Powers R. The oral health status of individuals on renal dialysis. Ann Periodontol.1998;3:197-205.

16. Peterson LJ, Ellis E III, Hupp JR, Tucker MR. Contemporary oral and maxillofacial surgery. 3rd ed. St. Louis: CV Mosby Co.; 2000.

17. Gudapati A, Ahmed P, Rada R. Dental management of patients with renal failure. Gen Dent 2002;50:508-510.

18. Werner CW, Saad TF. Prophylactic antibiotic therapy prior to dental treatment for patients with end-stage renal disease. Spec Care Dent 1999;19:106-111.

19. Lockhart PB, Gibson J, Pond SH, Leitch J. Dental management considerations for the patient with an acquired coagulopathy. Part 1: Coagulopathies from systemic disease. Br Dent J 2003;195:439-445.

20. Carranza FA, Newman MG. Clinical periodontology. 8th ed. Philadelphia: WB Saunders Company; 1996.

Accepted October 10, 2005 